\title{
Strategies of cooperation and punishment among students and clerical workers
}

\author{
Maria Bigoni, Gabriele Camera, and Marco Casari*
}

29 November 2012

\begin{abstract}
We study the individual behavior of students and workers in an experiment where they repeatedly face the same cooperative task. The data show that clerical workers differ from college students in overall cooperation rates, strategy adoption and use of punishment opportunities. Students cooperate more than workers. Cooperation increases in both subject pools when a personal punishment option is available. Students are less likely than workers to adopt strategies of unconditional defection, and more likely to select strategies of conditional cooperation. Finally, students are more likely than workers to sanction uncooperative behavior by adopting decentralized punishment, and also personal punishment when available.
\end{abstract}

Keywords: Non-standard subject pools, prisoner's dilemma, peer punishment, artefactual field experiment, stranger matching.

JEL codes: $\mathrm{C} 90, \mathrm{C} 70, \mathrm{D} 80$

\footnotetext{
* Bigoni: University of Bologna, Piazza Scaravilli 2, 40126 Bologna, Italy, Phone: +39-051-2098122, Fax: +39-0510544522, maria.bigoni@unibo.it; Camera: University of Basel and Chapman University, gabriele.camera@unibas.ch; Casari: University of Bologna, Piazza Scaravilli 2, 40126 Bologna, Italy, Phone: +39051-209-8662, Fax:+39-051-209-8493, marco.casari@unibo.it.

We thank for their comments two anonymous referees, the participants at the conference "Experimental Economics, Accounting and Society: A Conference in Memory of John Dickhaut" and especially Bart Wilson, who acted as a discussant. Camera thanks the NSF for research support through the grant CCF-1101627. Financial support for the experiments was also partially provided by a grant from Purdue's CIBER.
} 


\section{Introduction}

Cooperation - acting for the joint benefit of a group - is a key issue in the social and behavioral sciences, and it has been studied extensively by experimental economists. Achieving cooperation is especially challenging when individuals cannot develop personal ties, thus interacting as "strangers." There are still two aspects of cooperation in groups of strangers, which are relatively unexplored in experiments. First, whether results that emerge from studies based on a typical population of undergraduate students can be generalized to non-standard subject pools, which are characterized by a wider array of life and work experiences. Second, if and how adding a personal punishment opportunity to a standard social dilemma affects the strategies adopted at the individual level. We address these substantive and methodological issues by carrying out a study of cooperation, in which the task is repeated indefinitely and subjects cannot rely on reputation. The patterns of behavior of college students are compared to those of white-collar workers, in treatments with and without a personal punishment opportunity. The benchmark subject pool in the experiment consisted of undergraduate students from various disciplines at Purdue University, a large U.S. university. The non-standard subject pool comprised clerical workers employed as staff throughout Purdue University. These workers were mostly long-time local residents who exhibited a wide variation in age and educational backgrounds and did not have prior experience with laboratory experiments. ${ }^{1}$

In the experiment, pairs of subjects played a prisoner's dilemma either with or without the opportunity to engage in personal punishment. They interacted as strangers for an indefinite number of periods: subjects could neither identify the person they were matched with, nor see

\footnotetext{
${ }^{1}$ Some student participants had previous experience with laboratory experiments. One may conjecture that a common experience that cooperation in experimental tasks tends to yield higher earnings could have influenced behavior. We thank a referee for pointing this out. Overall, we did not have precise ex-ante expectations about how workers would be different from students.
} 
their history of play. According to folk theorem-type results, this setting admits multiple equilibria, including one with $100 \%$ cooperation (Kandori, 1992, Ellison, 1994). Indefinite repetition helps to overcome the short-run temptation to cheat others. This is the case if players adopt a norm of behavior based on the threat of relentless decentralized punishment, i.e., they permanently cease to cooperate after seeing just one defection; this is called the "grim" strategy. Here, personal punishment is theoretically neither necessary nor sufficient to sustain cooperation with identical, rational, and self-regarding agents. Evidence from previous studies indicates that cooperation levels are low when subjects do not know each other and cannot build reputations (e.g., Ostrom, 2010), and cooperation increases substantially when there are personal punishment opportunities (e.g., Ostrom, et al. 1992, Fehr and Gaechter, 2000).

Our design closely reflects the decentralized trading environment in Kandori (1992) and Ellison (1994). This generates theoretical predictions that serve as a reference in the interpretation of the empirical findings. In the paper, we assess (i) the strategies adopted by individuals in each subject pool, (ii) how students and workers differ in their ability to achieve cooperation, when many cooperation rates are supported in equilibrium, and (iii) how the additional opportunity to inflict a personal punishment affects individual strategies.

The design is as follows. Each participant played a supergame of indefinite duration within a group of four subjects. In every period, the group was randomly partitioned into two pairs of subjects and every pair played a prisoner's dilemma (PD). In the literature, the PD is the standard platform for studies on cooperation. The interaction was anonymous and subjects could only observe actions and outcomes in their own pair. Hence, even though each group interacted repeatedly, this design made it impossible for a single participant to build an individually identifiable reputation. Because of the random matching process, all participants could do was to 
form a general assessment about what to expect from the average member of their group. We call this setting a "strangers" design. This setting excludes reputation-based strategies as an explanation for cooperation, and brings to the forefront strategies that do not discriminate individuals based on their identity. As an additional advantage, this stranger design facilitates the identification of strategies adopted by subjects, because it exposes participants to a variety of counterparts.

We also introduced in the experiment the possibility of adopting personal punishment. Each subject had the costly opportunity to immediately respond to a counterpart's action by lowering her payoff in the period. Cooperators and defectors alike could be punished. We are especially interested in studying if and how subjects use personal punishment to complement or to substitute for decentralized sanctioning schemes that rely on future defections.

In previous work (Camera, Casari, and Bigoni, 2012), we questioned the empirical validity of the theoretical notion that play is homogeneous and that subjects implicitly coordinate on full cooperation when such an equilibrium is available. This previous study revealed that the behavior of only one out of four subjects was consistent with the use of the grim trigger strategy. It also revealed that, as subjects gained experience with the game, they kept experimenting with different strategies and managed neither to achieve full cooperation nor to coordinate on cooperative strategies.

This paper moves forward the study of equilibrium selection and individual strategy adoption in two directions. First, it explicitly compares aggregate and individual behavior of two diverse subject-pools. Second, it extends the analysis of strategies from a case where subjects can only resort to decentralized punishment, to a design in which they also have the opportunity to engage in personal punishment. We report substantial differences between subject pools; both in 
aggregate and individual behavior, and in the design with and without the personal punishment opportunity. Students exhibit higher levels of aggregate cooperation than workers. Students are also less likely than workers to adopt unconditional strategies, and more likely to select strategies of conditional cooperation. Finally, students are more inclined than workers to sanction defections through decentralized punishment and personal punishment, when available.

\section{Related experimental literature}

Our study is related to the experimental literature about differences in behavior and in strategies adopted by subjects with different socio-demographic characteristics. One methodological issue still open in this literature is whether results from a standard undergraduate population generalize to other populations, a question which is related to the external validity of experimental results (Harrison and List, 2004, Ball and Cech, 1996). There are only a few published studies on games of trust and cooperation, which compare students to non-student samples; the main message is that students are less cooperative and that age tends to be negatively correlated with cooperation.

The literature on public good games indicates that students contribute on average less than non-students. This result is supported by several studies involving non-student subjects (e.g., Carpenter and Seki, 2006, Egas and Riedl, 2008). See also Burks et al. (2009), for a one shot prisoners' dilemma game with student and non-student populations. Students also tend to cooperate less than non-students in trust and investment games, exhibiting a less trusting and trustworthy behavior (e.g., Fehr and List 2004, Bellemare and Kroeger, 2007). Overall, there is evidence that age is positively related to trust and trustworthiness (e.g., Gaechter et al., 2004, Sutter and Kocher, 2007, Hannan et al., 2002). 
A growing number of experimental studies collect empirical evidence about strategy adoption in indefinitely repeated social dilemmas. Most of these studies involve a short time horizon and a subject pool of undergraduate students only (e.g., Kurzban and Houser, 2005, Engle-Warnick and Slonim, 2006, Dal Bó and Fréchette, 2009, Fudenberg et al., 2012, Davis et al., 2011). In contrast, our design is based on a game with a longer horizon and it includes workers as participants. It complements and extends the works in Camera and Casari (2009), on the impact of information on cooperation, and in Camera, Casari, and Bigoni (2012), on individual strategy adoption in a standard subject pool. The current paper presents two main elements of novelty relative to the aforementioned studies. First, here we study how the availability of personal punishment affects strategy adoption; personal punishment is known to strongly affect aggregate behavior, although not much is known about how it affects individual strategies. Second, we investigate whether there are any subject-pool specificities in strategy adoption and realized cooperation levels.

The experimental literature on the effects of punishment on cooperation has mostly focused on one-shot and finitely repeated social dilemmas. Subjects display a tendency to engage in costly personal punishment of others, especially of defectors. Although this behavior is inconsistent with personal income maximization, it has been shown to be remarkably robust (e.g., Ostrom et al, 1992, Casari and Luini, 2009). We examine whether and how this behavioral trait impacts on the strategies adopted to sustain cooperation in an indefinitely repeated game, where subjects can also use a decentralized punishment scheme to police defections. A decentralized punishment scheme consists of indiscriminately punishing every group member in every period that follows a defection, not just the counterpart who actually defected. 


\section{Experimental design}

The experiment consists of four treatments, characterized by a different combination of two treatment variables: the availability of a personal punishment option (no punishment, NP, or personal punishment, PP) and the nature of the subject pool (students or workers). Continuation probability, stage game parameters, matching protocols, and private monitoring are kept constant. The NP treatment is a baseline environment designed to study strategy selection in an indefinitely repeated prisoner dilemma among strangers, where individual reputation formation is impossible. In an additional treatment (PP treatment), we also study how behavior is influenced by the availability of punishment institutions, i.e., when subjects have the option to use personal punishment. ${ }^{2}$ To investigate whether realized outcomes and adopted individual strategies vary across different subject pools, we ran experiments with undergraduates and white collar workers. Below we describe the stage game, the continuation probability and the matching protocols, which are identical across treatments.

Each participant played a supergame within a group of four persons who interacted privately and anonymously. In each period, subjects were randomly matched in pairs. As we will employ noncooperative equilibrium theory to develop theoretical predictions, we refer to a subject's counterpart in a pair as the "opponent." The interaction was private because subjects could only observe the outcomes of their pair. The interaction was anonymous because subjects could not observe identities; thus, building an individual reputation was impossible.

The stage game was the prisoners' dilemma described in Table 1. In the experiment, subjects could choose between C (=Cooperate) and D (=Defect). The parameters of the experiment were calibrated to promote some cooperative choices, a feature that is necessary to

\footnotetext{
${ }^{2}$ These two treatments respectively correspond to the Private Monitoring and Private Monitoring with Personal Punishment treatments in Camera and Casari (2009).
} 
uncover the strategies that participants adopt to support cooperative outcomes. ${ }^{3}$

\begin{tabular}{ccc}
\hline Player 1 & Cooperate & Defect \\
Player 2 & & \\
\hline Cooperate & 25,25 & 5,30 \\
Defect & 30,5 & 10,10 \\
\hline
\end{tabular}

Table 1: The stage game

Notes to Table 1: the labels in the instructions were $\mathrm{Y}$ for Cooperate and $\mathrm{Z}$ for Defect

A supergame (or cycle, as in the instructions) consisted of an indefinitely repeated interaction among subjects, achieved by a random continuation rule; see Roth and Murninghan (1978) or Palfrey and Rosenthal (1994). To implement this rule, at the end of each period the program drew a random integer between 1 and 100, using a uniform distribution. The cycle continued with a draw of 95 or below. Hence, in each period a cycle continued with a constant probability $\delta=0.95$. For a risk-neutral subject $\delta$ represents the discount factor. In each period, the cycle was expected to continue for 19 additional periods. All session participants observed the same random draw, meaning that cycles terminated simultaneously for all the economies.

Each experimental session comprised twenty subjects and five cycles. We built twenty-five economies in each session by creating five groups of four subjects in each of the five cycles. Matching across cycles followed a perfect stranger protocol: in each cycle each group included only subjects who had neither been part of the same group in previous cycles nor were part of the same group in future cycles. Subjects were informed that no two participants would ever interact together for more than one cycle. With this matching protocol across cycles, we can consider each subject as having five distinct "lives" in a session.

In every cycle, the participants of each four-subjects group interacted in pairs as follows. At

\footnotetext{
${ }^{3}$ The parameterization in Table 1 was selected as it scores high on the indexes proposed by Rapoport and Chammah (1965) and Roth and Murnighan (1978), and those indexes correlate with the level of cooperation in the indefinitely repeated prisoners' dilemma in a partner protocol.
} 
the beginning of each period of the cycle, the group was randomly divided into two pairs. In every period, each subject had one third probability of meeting any other participant. For the entire cycle, a subject exclusively interacted with the members of her group. In each group, subjects could neither observe identities of their opponents, nor communicate with each other, nor observe the histories of others. As a consequence, the subjects did not share a common history. ${ }^{4}$

The PP treatment introduced an additional punishment possibility to the baseline design; we call it "personal punishment" to differentiate it from the decentralized punishment scheme discussed earlier, which on the other hand involves the entire group. Subjects could lower the opponent's earnings, at a cost. This was done by adding a second stage to the game played in each round. The first stage was the prisoners' dilemma in Table 1. After observing the outcome in the prisoner's dilemma, both subjects in the pair had the opportunity to pay 5 points to reduce the opponent's earnings by 10 points. These decisions were simultaneous. Outside the pair, no one could observe outcomes or actions, including personal punishment.

The second treatment variable is the subject pool. The experiment involved two distinct groups of subjects: 80 undergraduate students from various disciplines at Purdue University and 80 clerical workers employed as staff throughout Purdue University. Undergraduates have a strong international component, while clerical workers are mostly long-time state residents, who exhibit a wide variation in age and educational background. Table 2 reports a summary of the main demographic characteristics of the two subject pools.

\footnotetext{
${ }^{4}$ This experimental design expands the scope of the analysis when it comes to designs for two-person groups. First, subjects face a wider variety of behavior, which facilitates the empirical identification of strategies. Second, we can investigate strategies that are not based on reputation, since we can control anonymity. Third, it allows investigation of how subjects coordinate on outcomes and strategies in situations where coordination is more challenging than in two-member groups.
} 
We ran two sessions per treatment. Each session had 20 participants and 5 cycles. The 80 student subjects were recruited through e-mail and in-class-announcements. The 80 worker subjects were recruited through e-mails targeted to administrative and technical staff across the West Lafayette campus. Each subject participated in only one session. Some students had previously participated in other types of economics experiments, while none of the workers had. Sessions were run in the Vernon Smith Experimental Economics Lab at Purdue University. No eye contact was possible among subjects. Instructions were read aloud with copies on all desks; a copy of the instructions can be found in Appendix B. The experiment was programmed using zTree (Fischbacher, 2007). Average earnings were \$18, excluding show-up fees. A session lasted on average 84 periods, for a running time of about 2 hours, including instruction reading and a quiz. $^{5}$

\begin{tabular}{|c|c|c|c|c|}
\hline & \multicolumn{2}{|c|}{ Students $(\mathrm{N}=80)$} & \multicolumn{2}{|c|}{ Workers $(\mathrm{N}=80)$} \\
\hline & Average & Missing & Average & Missing \\
\hline Male & $53.8 \%$ & 0 & $63.6 \%$ & 3 \\
\hline Age & 21.2 & 10 & 37.4 & 14 \\
\hline Married & $5.0 \%$ & 40 & $50.6 \%$ & 3 \\
\hline With children & $2.5 \%$ & 40 & $53.3 \%$ & 5 \\
\hline Gross family income $>\$ 50,000$ & $65.2 \%$ & 57 & $43.5 \%$ & 18 \\
\hline Home owner & $5.0 \%$ & 40 & $64.0 \%$ & 5 \\
\hline Education: college or higher & $10.0 \%$ & 40 & $57.1 \%$ & 3 \\
\hline Work experience (years) & 2 & 0 & 13.5 & 0 \\
\hline
\end{tabular}

\footnotetext{
${ }^{5}$ Sessions took place on the following dates for NP: 21.4 .05 (71) and 7.9.05 (104) with undergraduates, 29.11.05 (80) and 06.12.05 (50) with clerical workers; for PP: 28.04 .05 (139) and 06.09.05 (99) with undergraduates, 8.12 .05 (56) and 13.07.06 (77) with clerical workers. In parenthesis we report the total number of periods for the session. Show-up fees are as follows: students received $\$ 5$ (\$0 on 06.09.05); clerical workers received $\$ 5$ in the PP and $\$ 10$ in the NP treatments. Data of the first two sessions in treatments NP and PP are also analyzed in Camera and Casari (2009), which however does not analyze individual strategies. Data of all sessions of the NP treatment are also analyzed in Camera, Casari and Bigoni (2011).
} 


$\begin{array}{lllll}\text { Foreign born } & 18.9 \% & 43 & 7.7 \% & 2\end{array}$

\section{Table 2. Demographic characteristics}

Notes to Table 2: Data are self-reported by subject in the questionnaire. Some observations are missing because subjects either did not respond, or had a different version of the questionnaire.

\section{Theoretical considerations}

Here we offer theoretical equilibrium considerations, based on the Folk theorem-type results proved in Kandori (1992) and Ellison (1994) for random matching economies. ${ }^{6}$

Consider identical, self-regarding and risk-neutral players. The stage game is a prisoner's dilemma where total surplus in the group is maximized when everyone chooses $C$ (=efficient outcome) and hence earns $c=25$, and minimized when everyone selects $D$ (=inefficient outcome) and earns $d=10$. The Nash equilibrium is unique and corresponds to the inefficient outcome.

Indefinite repetition of the stage game with random participants supports a large set of sequential equilibrium outcomes. We discuss two equilibria. First, the strategy "always defect" is always a sequential equilibrium, because $D$ is a best response to play of $D$ by any randomly chosen opponent. In this inefficient outcome everyone earns $d$ in each period, hence the payoff is $d /(1-\delta)$. Second, if $\delta$ is sufficiently high, then $100 \%$ cooperation can be sustained in each period as a sequential equilibrium (Kandori 1992, Ellison 1994). In this efficient outcome every player earns the payoff $c /(1-\delta)$. More precisely, let $\delta^{*} \in(0,1)$ be the unique value of $\delta$ that satisfies

$$
\delta^{2}(h-d)+\delta(2 h-c-d)-3(h-c)=0 .
$$

Here $h=30$ is the payoff when the player defects while the opponent cooperates. If $\delta \geq \delta^{*}$, then the efficient outcome is a sequential equilibrium; this sufficient condition is satisfied in all experimental treatments because $\delta=0.95>\delta^{*}=0.443$.

\footnotetext{
${ }^{6}$ Details on derivations are in the Appendix to Camera and Casari (2009).
} 
To see how players can support the efficient outcome, consider a situation in which all players adopt the grim trigger strategy. This social norm is a rule of behavior that identifies a desirable play, and also a decentralized punishment scheme to be implemented if a departure from desirable play is ever observed. Put simply, each player starts cooperating and keeps cooperating, unless someone defects; in that case the player switches to a punishment phase consisting of "always defect." This triggers a contagious, indiscriminate and relentless punishment process. Although people may not ordinarily follow a grim trigger strategy in practice, theorists employ it widely when tracing the cooperation frontier in repeated games. Because defection is an absorbing state, such decentralized punishment threat ensures that noone deviates in equilibrium, as long as players sufficiently value future payoffs. This requires a sufficiently large discount factor $\delta$. In economies of four players, the absorbing state can be reached very quickly, hence $\delta^{*}$ is low.

Several remarks are in order. First, due to private monitoring, T-periods punishment strategies cannot support the efficient outcome as an equilibrium (see Ellison, 1994). Second, that same paper indicates that the efficient outcome could be sustained in our experiment also by adopting contagious punishment strategies that exploit the availability of a public randomization device. This is so because in every period all session participants observed the same random integer number, which could have served as a public randomization device. Third, cooperation is risk-dominant in our design, in the following sense. Compare the strategy "always defect" to "grim trigger"; grim trigger is risk-dominant if a player is at least indifferent to selecting it, given that everyone else is believed to select each of the two strategies with equal probability. Indifference requires $\delta=0.763$. 
Finally — and most importantly — in our private-monitoring economies the use of personal punishment is neither necessary nor sufficient to sustain the efficient outcome as an equilibrium among identical, self-interested agents. The personal punishment opportunity gives players the (costly) option to lower their opponents' earnings, after observing the outcome of the prisoners' dilemma. In one-shot interactions, using personal punishment is a dominated action because it is costly for the punisher. Given indefinite repetition, personal punishment is not theoretically necessary, for two reasons. First, players can adopt the social norm based on grim trigger to sustain the efficient outcome. Second, the use of personal punishment does not allow players to trigger a faster contagious process of defection, because actions cannot be observed outside a match. On the other hand, the use of personal punishment alone is not theoretically sufficient to sustain the efficient outcome because it is not credible, although it could be used in combination with the threat of switching to harsher punishments (e.g., a penal code-type of strategy that presumes a switch to "always defect" if a defector is not sanctioned with personal punishment). In short, standard theoretical arguments do not suggest that personal punishment facilitates the emergence of a cooperative outcome.

\section{Estimation procedures for individual strategies}

This section describes the methodology adopted for the empirical identification of the strategies employed by individuals in the experiment. The unit of observation is the sequence of all choices made by a subject in a cycle (=an individual); we may also refer to such a sequence as one observation. Hence, each subject in the experiment contributed five observations to the dataset.

In this repeated game there are infinitely many strategies. The data analysis in this paper focuses on twelve strategies, some of which are consistent with equilibrium behavior, while 
others are not (Table 3). Consider that any type of behavior observed in the experiment can be described by a sufficiently complex strategy. We used the following approach to select the twelve strategies. First, we have considered strategies that rely neither on personal punishment nor on personal punishment histories; as noted earlier, personal punishment is neither necessary nor sufficient to sustain the efficient outcome, hence we study the use of personal punishment separately from the behavior in the prisoner's dilemma. Second, we have included the two unconditional strategies "always defect" and "always cooperate," as well as ten conditional strategies of cooperation for which there is already some empirical support (Dal Bó and Fréchette, 2011, Fudenberg et al., 2012, Camera, Casari and Bigoni, 2012). The ten conditional strategies allow us to gauge the complexity of subjects' behavior, since they include strategies that condition on short as well as on longer histories of play. We included "tit-for-tat" and "grim trigger", and eight longer-memory versions of such strategies that exhibit either a longer fuse to triggering the punishment phase or a longer punishment phase.

\begin{tabular}{|r|l|}
\hline \multicolumn{1}{|c|}{ Strategy } & \multicolumn{1}{|c|}{ Description } \\
\hline Unconditional & \\
\hline Always cooperate & Always choose C (=cooperate) \\
\hline Always defect & Always choose D (=defect) \\
\hline Unforgiving & \\
\hline Grim trigger & Cooperate until an opponent defects, and then switch to "always defect." \\
\hline Grim2-A & Cooperate until 2 opponents defect, and then switch to "always defect." \\
\hline Grim2-B & $\begin{array}{l}\text { Cooperate until 2 opponents consecutively defect, and then switch to } \\
\text { "always defect." }\end{array}$ \\
\hline Grim3-A & Cooperate until 3 opponents defect, and then switch to "always defect." \\
\hline Grim3-B & $\begin{array}{l}\text { Cooperate until 3 opponents consecutively defect, and then switch to } \\
\text { "always defect." }\end{array}$ \\
\hline
\end{tabular}




\begin{tabular}{|r|l|}
\hline \multicolumn{1}{|l|}{ Forgiving } & \\
\hline Tit for Tat (TFT) & Cooperate unless the previous opponent defected. \\
\hline Two-tits-for-tat (2TFT) & $\begin{array}{l}\text { Cooperate unless an opponent defected in any of the last 2 rounds (play D } \\
\text { for two consecutive rounds after a defection is observed) }\end{array}$ \\
\hline Tit-for-two-tats (TF2T) & Cooperate unless the opponents defected in each of the last 2 rounds. \\
\hline Three-tits-for-tat (3TFT) & $\begin{array}{l}\text { Cooperate unless an opponent defected in any of the last 3 rounds (play D } \\
\text { for three consecutive rounds after a defection is observed) }\end{array}$ \\
\hline Tit-for-three-tats (TF3T) & Cooperate unless the opponents defected in each of the last 3 rounds. \\
\hline
\end{tabular}

Table 3. Strategies considered

It is convenient to group the strategies listed in Table 3 into three distinct strategy sets. The first set includes strategies in which actions are unconditional on histories and prescribe the indefinite repetition of the same action in the prisoner's dilemma: "always cooperate" and "always defect." The remaining ten conditional strategies prescribe cooperation in the initial period, and we divide them into two sets. One includes unforgiving strategies, in which one or more observed defections triggers a switch to a permanent punishment phase; this comprises "grim trigger" and more lenient versions of such strategy, in which the switch to the punishment phase is triggered only if more than one defection is observed (consecutively and not). The last strategy set includes forgiving strategies, in which observed defections trigger a temporary punishment phase. This comprises "tit for tat" and more lenient or less forgiving variants that have either a delay in triggering to the punishment phase or have a longer punishment phase. While "Always Defect" and "Grim Trigger" are equilibrium strategies, other considered strategies, such as “Always cooperate," are clearly not.

We estimate the importance of each candidate strategy with a maximum likelihood approach, as in Dal Bó and Fréchette (2011) and Fudenberg et al. (2012). The estimation employs data from all cycles and presumes that (i) in a cycle, all subjects face the same probability distribution of adopting one of the 12 strategies considered, (ii) subjects may change strategy from cycle to 
cycle (but not within a cycle), and (iii) subjects may make errors in implementing actions, i.e., there is some probability (time-invariant, and identical across subjects) that a subject may choose an action that is not recommended by the strategy adopted. ${ }^{7}$

In the PP treatment subjects could use personal punishment to immediately respond to an opponent's action. We are especially interested in studying if and how subjects use personal punishment to complement or to substitute for sanctions based on defection. To this end, we have considered only strategies that condition on the outcome of the prisoner's dilemma in the first stage of the game, but do not condition on histories of play from previous periods. For simplicity, we have included only strategies that prescribe personal punishment solely if someone defected. ${ }^{8}$ Hence, we end up considering eight "punishment strategies", because personal punishment might be selected only in three possible outcomes of the prisoner's dilemma: $\mathrm{CD}, \mathrm{DC}$, and $\mathrm{DD}$. The prevalence of each of these eight punishment strategies is estimated using the same maximum likelihood approach.

\section{Results}

This section presents a comparison of outcomes and strategies for different subject pools. The findings are organized into five main results. The first result concerns the differences in overall cooperation rates across treatments. The second result illustrates the strategies adopted by the two subject pools in the treatments without personal punishment. The third and the fourth results describe students and workers' strategies in the treatments with personal punishment. Finally, the fifth result discusses subject-pool differences in the use of personal punishment.

\footnotetext{
${ }^{7}$ The estimation was executed adapting the code included in the supplementary material of Dal Bó and Fréchette (2011). The details of the estimation procedure are reported in Appendix A.

${ }^{8}$ This is because in the PP treatment, individuals used personal punishment in less than $0.5 \%$ of the periods in which $\mathrm{CC}$ was the outcome of the prisoner's dilemma.
} 
Result 1. Average cooperation rates are higher among students than workers in all treatments.

Figure 1 and Table 4 provide support for Result 1. Consider Figure 1: in the NP treatment, the cooperation rate in all periods is 16.1 percentage points higher for students than for workers; ${ }^{9}$ when restricting attention to the first period of each cycle, the cooperation rate is 10.5 percentage points higher for students than for workers. Table 4 reports the results of formal tests to assess the significance of such differences in cooperation rates; the difference in cooperation rates across all periods is significant at the $5 \%$ level (column 1), but is not significant when considering only the first period (column 2).

A similar finding emerges from the PP treatment. Students' cooperation rate is 11.1 percentage points higher than workers' in all periods, and 11 percentage points higher when considering only the first period of each cycle. Differences are significant at the $5 \%$ and $1 \%$ levels, respectively (Table 4, column 2).

\footnotetext{
${ }^{9}$ For cycle $k=1, . ., K$ of a session, define the action of subject $j=1, . ., \mathrm{J}$ in period $t=1, . ., T^{k}$ as $a_{i t}{ }^{k}=0,1$, where 1 is cooperation. The cooperation rate of subject $j$ is $c_{j}=\sum_{k=1}^{K} \sum_{t=1}^{T^{k}} a_{t j}{ }^{k} / \sum_{k=1}^{K} T^{k}$ between 0 and 1 (reported in \%), and across subjects is $c=\sum_{j=1}^{J} c_{j} / J$. So, if cycles have different length $T^{k}$, then they receive different weight in the measure $c$ of average cooperation.
} 


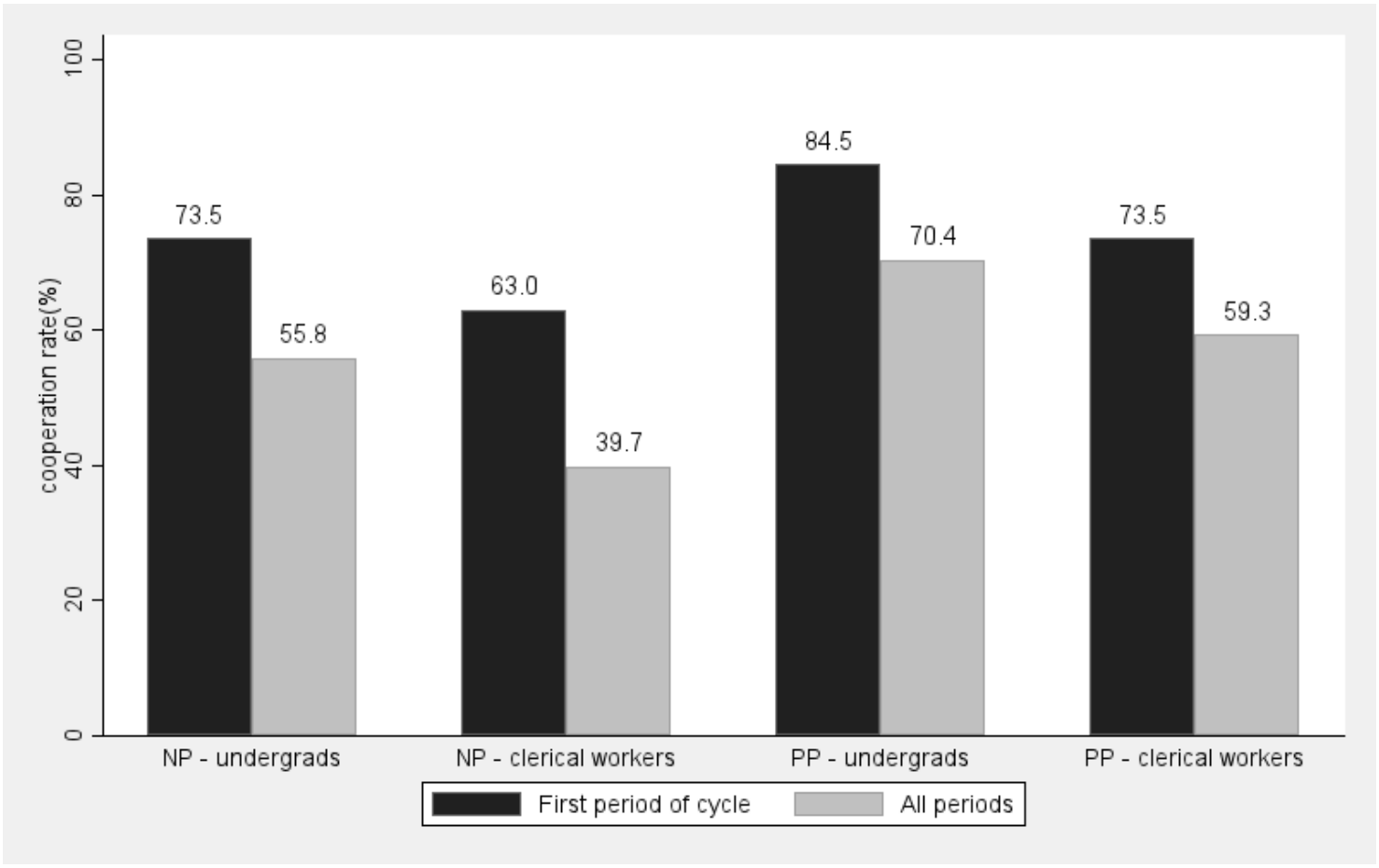

Figure 1. Cooperation rates

Notes to Figure 1: $\mathrm{NP}=$ treatment without personal punishment; $\mathrm{PP}=$ treatment with personal punishment. Cooperation rates are calculated across all periods of all cycles, first by dividing the number of periods of all five cycles in which a subject cooperated by the total number of periods played, then by taking the average across subjects. This implies that the weight of each cycle on the cooperation rate in a session is proportional to its length, but all the sessions in the treatment are equally weighted.

\begin{tabular}{lcc}
\hline & All periods & Periods 1 \\
\cline { 2 - 3 } & $\begin{array}{c}\text { Coefficient } \\
(\text { s.e. })\end{array}$ & $\begin{array}{c}\text { Marginal effect } \\
(\text { s.e. })\end{array}$ \\
\hline PP treatment & $0.142^{* *}$ & 0.127 \\
& $(0.055)$ & $(0.102)$ \\
Worker $\times$ NP treatment & $-0.164^{* *}$ & -0.092 \\
& $(0.053)$ & $(0.094)$ \\
Worker $\times$ PP treatment & $-0.125^{* *}$ & $-0.127^{* * *}$ \\
Constant & $(0.041)$ & $(0.047)$ \\
& $0.570^{* * *}$ & --- \\
Observations & $(0.046)$ & \\
R-squared & & \\
Pseudo-R squared & 800 & 800 \\
\hline
\end{tabular}

Table 4. Initial and average cooperation rates

Notes to Table 4: The second column reports the marginal effects obtained by a logit regression where the dependent variable is the binary decision to cooperate $(=1)$ or defect $(=0)$ in period 1 of each cycle. The first column 
reports the estimated coefficients from an OLS regression in which the dependent variable is the average cooperation rate for each individual (i.e., for each subject in a cycle). In this OLS regression, each observation is weighted for the length of the cycle it belongs to, so cycles with longer length have more weight. In both regressions, we include three independent variables, which capture treatment effects. The first regressor is a dummy that takes value 1 in the treatment with Personal Punishment, and zero otherwise. The second and third regressors interact the dummy "worker" (taking value 1 for subjects who are not undergraduate students, zero otherwise) with the two dummies for the NP and PP treatment. These last two regressors capture the difference in average cooperation rates between students and workers, in the distinct cases with and without personal punishment. We obtain qualitatively similar results by running a Tobit regression instead of an OLS regression. Regression results for this robustness check are available from the authors upon request. In parenthesis we report standard errors robust for clustering at the session level: * significant at $10 \% ; * *$ significant at $5 \% ; * * *$ significant at $1 \%$.

Result 2. In the treatment without personal punishment, students and workers differ in their strategy adoption. Workers do not select "always defect" as frequently as students, and they also select "forgiving" strategies less frequently. Differences between students and workers, however, are not significant.

Support for Result 2 comes from Table 5, which reports the maximum likelihood estimates of the population proportions for each of the 12 strategies considered. For both samples, the most frequent single strategy is "always defect," followed by "always cooperate." Hence, unconditional strategies prevail among subjects.

\begin{tabular}{|c|c|c|c|c|}
\hline \multirow[b]{2}{*}{ Strategy } & \multicolumn{2}{|c|}{ Students } & \multicolumn{2}{|l|}{ Workers } \\
\hline & Coefficient & s.e. & Coefficient & s.e. \\
\hline \multicolumn{5}{|l|}{ Unconditional } \\
\hline Always cooperate & $0.177 * * *$ & 0.039 & $0.164 * * *$ & 0.024 \\
\hline Always Defect & $0.238 * * *$ & 0.060 & $0.366 * * *$ & 0.051 \\
\hline \multicolumn{5}{|l|}{ Unforgiving } \\
\hline Grim trigger & $0.061 * *$ & 0.025 & $0.101 *$ & 0.052 \\
\hline Grim2-A & $0.021 *$ & 0.012 & $0.088 * * *$ & 0.031 \\
\hline Grim2-B & $0.060 * *$ & 0.024 & 0.000 & 0.015 \\
\hline Grim3-A & $0.049 * * *$ & 0.018 & 0.000 & 0.000 \\
\hline Grim3-B & $0.099 * * *$ & 0.023 & $0.083 * *$ & 0.033 \\
\hline \multicolumn{5}{|l|}{ Forgiving } \\
\hline Tit for Tat & $0.078 * * *$ & 0.017 & 0.054 & 0.034 \\
\hline $2 \mathrm{TFT}$ & $0.034 * * *$ & 0.010 & 0.000 & 0.013 \\
\hline TF2T & $0.057 * *$ & 0.025 & $0.076 *$ & 0.046 \\
\hline 3TFT & 0.026 & 0.018 & 0.030 & 0.024 \\
\hline TF3T & $0.101 *$ & & $0.037 *$ & \\
\hline gamma & $0.438 * * *$ & 0.014 & $0.619 * * *$ & 0.057 \\
\hline Log-likelihood & 1319.767 & & 1359.284 & \\
\hline $\mathrm{N}$ & 200 & & 200 & \\
\hline
\end{tabular}




\section{Table 5. Maximum Likelihood Estimation of strategy adoption (NP treatment)}

The estimated shares of "always defect" are $23.8 \%$ for students and $36.6 \%$ for workers (p-value: 0.1012 ); the shares of "forgiving" strategies are $29.6 \%$ for students and $19.7 \%$ for workers (pvalue: 0.4143$).^{10}$

Table 5 also reports the estimate for the parameter $\gamma$, which controls the variance of the error distribution in implementing the action prescribed by the selected strategy. This variance is significantly higher among workers than students (p-value: 0.0020), which suggests that it is more difficult to capture workers' behavior through the set of strategies considered.

Result 3: In the treatment with personal punishment, students cooperate more than in the treatment without. When personal punishment is available, students adopt unforgiving strategies more frequently and "always defect" less frequently.

Figure 1 shows that, considering all periods, the cooperation rate for students increases from 55.8 percent in the NP treatment to 70.4 percent in the PP treatment, as already noted in Camera and Casari (2009). This difference is significant at the 5\% level (Table 4). The maximum likelihood estimation of strategies helps us to understand why this happens, as it describes a substantial change in the adopted strategies. It is important to recall that the strategies estimated in Table 5 explicitly focus on patterns of behavior in the prisoners' dilemma and do not condition on personal punishment; the use of personal punishment is analyzed later. Students are less likely to adopt unconditional strategies when personal punishment is available; the estimated share of

\footnotetext{
${ }^{10}$ As in Fudenberg et al. (2012, footnote 38) we report the results of a two-sample $t$-test using bootstrapped standard errors of the aggregated coefficients. We cannot compute the test for the set of "forgiving strategies", as the standard error for strategy TF3T is not directly estimated. In this case, we report the $t$-test using the aggregated coefficients and the standard errors for the other strategies that are not included among the set of "forgiving strategies".
} 
"always cooperate" drops a few points, while the estimated share of "always defect" dramatically drops from $23.8 \%$ to $7.8 \%$ (see Table 5 vs. Table 6 , p-value: 0.0091 ). The data show a substantial increase both in the share of "unforgiving" strategies (from $29.0 \%$ to $38.4 \%$, p-value: 0.0659 ) and in the share of "forgiving" strategies (from $29.6 \%$ to $41.8 \%$, p-value: 0.2291 ). The availability of personal punishment seems to motivate students to make an attempt at coordinating on cooperation. This is done by adopting strategies that start with cooperation and prescribe a switch to a punishment phase only after one or more defections are observed.

Interestingly, the increase in cooperation rates is associated with the adoption of conditional rather than unconditional cooperative strategies. One could have conjectured that what sustained high cooperation in the PP treatment was the "always cooperate" strategy, together with the use of personal punishment targeted to defectors. The estimation of individual strategies adopted by students provides no support for this conjecture. As shown below, the data exhibit different patterns for workers.

\begin{tabular}{|c|c|c|c|c|}
\hline \multirow[b]{2}{*}{ strategy } & \multicolumn{2}{|c|}{ Students } & \multicolumn{2}{|c|}{ Workers } \\
\hline & Coefficient & s.e. & Coefficient & s.e. \\
\hline \multicolumn{5}{|l|}{ Unconditional } \\
\hline Always cooperate & $0.120 * * *$ & 0.028 & $0.264 * * *$ & 0.045 \\
\hline Always defect & $0.078 * * *$ & 0.013 & $0.254 * * *$ & 0.024 \\
\hline \multicolumn{5}{|l|}{ Unforgiving } \\
\hline Grim trigger & $0.078 * * *$ & 0.025 & $0.054 * * *$ & 0.015 \\
\hline Grim2-A & $0.065 * *$ & 0.029 & $0.106 * * *$ & 0.022 \\
\hline Grim2-B & $0.128 * * *$ & 0.049 & 0.000 & 0.002 \\
\hline Grim3-A & $0.016 *$ & 0.010 & 0.000 & 0.000 \\
\hline Grim3-B & $0.097 * * *$ & 0.027 & $0.122 * * *$ & 0.035 \\
\hline \multicolumn{5}{|l|}{ Forgiving } \\
\hline Tit for Tat & $0.120 * * *$ & 0.022 & 0.019 & 0.018 \\
\hline 2TFT & 0.000 & 0.001 & $0.060 * * *$ & 0.022 \\
\hline TF2T & $0.185 * * *$ & 0.035 & 0.023 & 0.014 \\
\hline $3 \mathrm{TFT}$ & 0.024 & 0.022 & 0.000 & 0.005 \\
\hline TF3T & $0.089 * * *$ & & $0.099 * * *$ & \\
\hline gamma & $0.420 * * *$ & 0.026 & $0.564 * * *$ & 0.028 \\
\hline Log-likelihood & 1504.425 & & 1288.470 & \\
\hline $\mathrm{N}$ & 200 & & 200 & \\
\hline
\end{tabular}

Table 6. Maximum Likelihood Estimation of strategy adoption (PP treatment). 
Result 4: In the treatment with personal punishment, workers cooperate more than in the treatment without punishment. When personal punishment is available, workers follow "always cooperate" more frequently and "always defect" less frequently.

Figure 1 shows that, considering all periods, the cooperation rate for workers increases from $39.7 \%$ in the NP treatment to $59.3 \%$ in the PP treatment (a test on the estimated coefficients in Table 4 indicates that the difference is significant $t$ the $1 \%$ level). The impact of the availability of personal punishment on overall cooperation rates is therefore similar across subject pools. However, the impact on strategy adoption is qualitatively different.

Workers are less likely to adopt "always defect" and more likely to adopt "always cooperate" when personal punishment is available (see Table 5 vs. Table 6). The estimated shares drop from $36.6 \%$ to $25.4 \%$ for "always defect" (p-value: 0.0469 ) and increase from $16.4 \%$ to $26.4 \%$ for "always cooperate" (p-value: 0.0505). The changes are approximately of the same magnitude, and only minimal variations appear for "Forgiving" and "Unforgiving" strategies. A comparison of Tables 5 and 6 suggests that, in the case of workers, the availability of personal punishment options raises the prevalence of "always cooperate" by about 10 percentage points, while decreasing the prevalence of "always defect" by the same amount. One interpretation is that workers in our experiment substituted the cooperative for the uncooperative unconditional strategy.

Result 5: Workers use personal punishment less frequently than students.

The support for Result 5 is in Table 7, which reports results for a maximum likelihood estimation of the prevalence of the eight personal punishment strategies considered, separated by subject 
pool. In the experiment, the strategy that prescribes to never use personal punishment ("never punish") has a $62.8 \%$ share among workers and $44.1 \%$ among students. (p-value: 0.1425$)$. In both subject pools personal punishment is basically used only to sanction a defection of the opponent. The strategy that prescribes personal punishment only when the subject cooperates and the opponent defects ("punish cheaters"), is more widely adopted among students than workers $(38.7 \%$ among students vs. $21.9 \%$ among workers, p-value: 0.0951$)$. The share of students and workers who punish a defector when they have also defected ("punish all defections") is, instead, identical (p-value $\approx 1.000)$.

Given our previous Results 3 and 4, we can interpret this finding as an indication that the availability of personal punishment has a different impact on the way students and workers police deviations from cooperation. Students use personal punishment as a tool that complements decentralized punishment. Relative to the NP treatment, in the PP treatment students are more likely to adopt strategies that trigger a decentralized punishment phase (when a defection is observed), and to also use personal punishment on defectors. Instead, workers are more likely to adopt unconditional cooperative strategies in the PP than in the NP treatment, sanctioning defections with personal punishment rather than with decentralized punishment.

\begin{tabular}{|c|c|c|c|c|}
\hline \multirow[b]{2}{*}{ Personal punishment strategy } & \multicolumn{2}{|c|}{ Students } & \multicolumn{2}{|c|}{ Workers } \\
\hline & Coefficient & s.e. & Coefficient & s.e. \\
\hline Never punish (000) & $0.441 * * *$ & 0.064 & $0.628 * * *$ & 0.110 \\
\hline Punish cheaters (100) & $0.387 * * *$ & 0.062 & $0.219 * * *$ & 0.079 \\
\hline Punish all defections (101) & $0.116 * *$ & 0.048 & $0.116 * * *$ & 0.039 \\
\hline Always punish (111) & 0.036 & N.A. & 0.000 & N.A. \\
\hline Other punishment strategies & & & & \\
\hline$(001,010,011$, and 110$)$ & 0.021 & N.A. & 0.037 & N.A. \\
\hline$\gamma$ & $0.294 * * *$ & 0.018 & $0.345 * * *$ & 0.021 \\
\hline Log-likelihood & 748.661 & & 646.876 & \\
\hline $\mathrm{N}$ & 200 & & 200 & \\
\hline
\end{tabular}

Table 7. Maximum Likelihood Estimation on punishment strategies adoption 
Notes to Table 7: Punishment strategies are coded as follows: 0 means "do not punish", 1 means "punish". The first digit of the strategy is the action to be taken when the subject cooperates and the opponent defects. The second indicates the action to be taken when the subject defects and the opponent cooperates. The third indicates the action to be taken when the subject defects and the opponent defects.

\section{Conclusions}

This paper reports results from an experiment on social dilemmas that involved a pool of college students and one of clerical workers. It contributes to the literature on cooperation in two ways. First, a methodological contribution is associated to the discovery of differences in behavior across the subject pools. Most of the existing laboratory studies on this topic have been conducted only with college students as subjects. The data show that not all results from student subjects can be generalized. Workers in our experiment tended to cooperate with an overall lower frequency and to start defecting from the beginning of the game. In contrast, previous studies have found that students are on average less cooperative than other subject pools. There may be a variety of possible explanations. On the one hand, clerical workers may be a peculiar sample that differs from other samples of the adult population. Perhaps, these differences originate in a stronger orientation toward individual tasks, as these characterize clerical work. This may feed back in the clerical workers' ability to coordinate with others on cooperative tasks. On the other hand, our clerical workers did not have prior direct experience with laboratory experiments, unlike undergraduate students who might have learned, through participation in prior experiments, that cooperating could lead to higher earnings. Another possible explanation is that social dilemmas with known, deterministic duration may simply induce qualitatively different behavior than dilemmas in which duration is indefinite, as in our experiment.

A second contribution of the paper emerges from comparing the individual strategy adoption 
in the prisoner's dilemma, in treatments with and without a personal punishment opportunity. Workers were more likely to unconditionally cooperate in treatments with personal punishment than in treatments without it. On the contrary, the introduction of personal punishment made students more likely to adopt a cooperative strategy based on the threat of temporary punishment, i.e., to adopt "forgiving" strategies.

In the treatment with a personal punishment opportunity, there were additional remarkable differences between students and workers. Students no longer followed "always defect," while the prevalence of this uncooperative behavior among workers, albeit lower, remained strong. In general, personal punishment in the experiment was either not used or it was used to sanction defectors. There was virtually no anti-social punishment among both students and workers, i.e., defectors did not punish cooperators. The one difference is that workers were overall less likely than students to use personal punishment.

These findings show that, when faced with a cooperative task, dissimilar subject pools exhibit different strategy profiles. In particular, we observe two disparities. One the one hand, workers were less prone to adopt cooperative strategies. Even in treatments with personal punishment, no less than one fourth of the workers started by defecting and continued to defect unconditionally. On the other hand, workers were overall less inclined to follow strategies that sanctioned uncooperative behavior either by adopting decentralized punishment or personal punishment. These two findings may explain why we observed less cooperation among workers than among students.

This study suggests that one should be cautious about generalizing to other subject pools the results that emerge from studies conducted with college students. Although treatment differences across subject pools did not reverse the direction of the effect, quantitative estimates of results 
were at times far apart across subject pools, and went in an unexpected direction if compared to prior experiments. Being hard to identify a clear, specific factor behind the observed differences, this study calls for more experiments with non-standard subject pools, in order to further corroborate the robustness of findings from laboratory experiments. 


\section{References}

Ball, S.B., Cech, P., 1996. Subject pool choice and treatment effects in economic laboratory research. Research in Experimental Economics 6, 239-292.

Bellemare, C., Kroeger, S., 2007. On representative social capital. European Economic Review 51(1), 183-202.

Camera, G., Casari, M., 2009. Cooperation among strangers under the shadow of the future. American Economic Review 99(3), 979-1005.

Camera, G., Casari M., Bigoni, M., 2012. Cooperative Strategies in Groups of Strangers: An Experiment, Games and Economic Behavior, 2012, 75, 2, 570-586.

Carpenter, J., Seki, E., 2006. Competitive Work Environments and Social Preferences: Field Experimental Evidence from a Japanese Fishing Community. Contributions to Economic Analysis \& Policy 5(2), 1460-1460.

Casari, M., Luini, L., 2009. Cooperation under Alternative Punishment Institutions: An Experiment. Journal of Economic Behavior and Organization 71(2), 273-282.

Dal Bó, P., Fréchette, G., 2011. The Evolution of Cooperation in Infinitely Repeated Games: Experimental Evidence. American Economic Review 101, 411-429.

Davis, D., Ivanov, A., Korenok, O., 2011. A Simple Approach for Organizing Behavior and Explaining Cooperation in Repeated Games. Unpublished manuscript, Virginia Commonwealth University.

Egas, M., Riedl, A., 2008. The economics of altruistic punishment and the maintenance of cooperation. Proceedings of the Royal Society B: Biological Sciences 275(1637), 871-878.

Ellison, G., 1994. Cooperation in the Prisoner's Dilemma with Anonymous Random Matching. Review of Economic Studies 61, 567-588.

Engle-Warnick, J., Slonim, R., 2006. Inferring Repeated-Game Strategies from Actions: Evidence from Trust Game Experiments. Economic Theory 28, 603-632.

Fehr, E., Gächter, S., 2000. Cooperation and Punishment in Public Goods Experiments. The American Economic Review 90(4), 980-994.

Fischbacher, U., 2007. z-Tree: Zurich Toolbox for Ready-made Economic Experiments. Experimental Economics 10(2), 171-178.

Fudenberg, D., Rand D., Dreber, A., 2012. Slow to Anger and Fast to Forgive: Cooperation in an Uncertain World. American Economic Review 102(2), 720-749.

Gaechter, S., Herrmann, B., Thöni, C., 2004. Trust, voluntary cooperation, and socio-economic background: survey and experimental evidence. Journal of Economic Behavior \& Organization 55(4), 505-531.

Hannan, R.L., Kagel, J.H., Moser, D.V., 2002. Partial Gift Exchange in an Experimental Labor Market: Impact of Subject Population Differences, Productivity Differences, and Effort Requests on Behavior. Journal of Labor Economics 20(4), 923-951. 
Harrison, G., List, J., 2004. Field experiments. Journal of Economic Literature 42(4), 1009-1055. Kandori, M., 1992. Social Norms and Community Enforcement. Review of Economic Studies 59, 63-80.

Kurzban, R., Houser, D., 2005. An experimental investigation of cooperative types in human groups: A complement to evolutionary theory and simulations. Proceedings of the National Academy of Sciences 102(5), 1803-1807.

Ostrom, E., Walker, J., Gardner, R., 1992. Covenants With and Without a Sword: SelfGovernance is Possible. The American Political Science Review 86(2), 404-417.

Ostrom, E., 2010. Beyond markets and states: polycentric governance of complex economic systems. The American Economic Review 100(3), 641-672.

Palfrey, T.R., Rosenthal, H., 1994. Repeated Play, Cooperation and Coordination: An Experimental Study. Review of Economic Studies 61, 545-565.

Roth, A.E., Murnighan, K., 1978. Equilibrium Behavior and Repeated Play of The Prisoner's Dilemma. Journal of Mathematical Psychology 17, 189-98.

Sutter, M., Kocher, M.G., 2007. Trust and trustworthiness across different age groups. Games and Economic Behavior 59(2), 364-382. 


\section{Appendix A \\ Strategy estimation procedure}

To estimate the prevalence of each strategy in our dataset we use a standard maximum likelihood (ML) procedure, as in Dal Bó and Frechette (2011) and Fudenberg et al. (2011). There are two basic assumptions. First, each subject $j=1, \ldots, J$ (where $J=40$ in each of our four treatments) adopts the same strategy $k \in K$ in all periods of a cycle $n=1, \ldots, 5$. Subject $j$ may choose a different strategy in different cycles, unlike in Dal Bó and Frechette (2011) and Fudenberg et al. (2011). Therefore, we denote by $i \in I:=\{1, \ldots, 5 J\}$ the individual, i.e., a subject in a cycle. The individual is our unit of observation. Second, in every period, individual $i$ may make a mistake in choosing the action prescribed by the strategy adopted. This mistake is distributed identically and independently across individuals and periods.

More specifically, consider individual $i$ in period $t=1, \ldots, T^{i}$, where $T^{i}$ is individualspecific because cycles have generally different durations. Let $s_{t}^{i}(k)=-1,1$ denote the choice of individual $i$ in period $t$ if she follows strategy $k$; -1 indicates that $D$ should be implemented, and 1 indicates $C$. It is assumed that individual $i$ chooses $C$ if $y_{t}^{i}=1$ and chooses $D$ otherwise, where we define

$$
y_{t}^{i}:= \begin{cases}1 & \text { if } s_{t}^{i}(k)+\gamma \varepsilon_{t}^{i} \geq 0 \\ 0 & \text { otherwise. }\end{cases}
$$

Here $\varepsilon_{t}^{i}$ is an error term with probability density function such that the likelihood $P^{i}(k)$ that individual $i$ adopts strategy $k$ has a logistic distribution. The parameter $\gamma$ controls 
the variance of the error. Consequently, $\frac{1}{1+e^{-1 / \gamma}}$ is the probability that the action implemented by an individual in any period coincides with the actions prescribed by the strategy. Hence, the likelihood that individual $i$ adopts strategy $k$ is

$$
P^{i}(k)=\prod_{t=1}^{T^{i}}\left(\frac{1}{1+\exp \left(-s_{t}^{i}(k) / \gamma\right)}\right)^{y_{t}^{i}}\left(\frac{1}{1+\exp \left(s_{t}^{i}(k) / \gamma\right)}\right)^{1-y_{t}^{i}}
$$

The function we wish to maximize is the log-likelihood

$$
\sum_{i \in I} \ln \left(\sum_{k \in K} \pi_{k} P^{i}(k)\right)
$$

We estimate the parameter vector $\pi:=\left(\pi_{k}\right)_{k \in K}$ and the variance parameter $\gamma$ that maximize (1). The vector $\pi$ describes the probability distribution over the set $K$ of strategies. The estimated parameter $\hat{\pi}_{k} \in \hat{\pi}$, represents the proportion of individuals (or observations) that is attributed to strategy $k$, or, equivalently, the prevalence of each strategy in our dataset. The estimated parameter $\hat{\gamma}$ provides a measure of the probability of mistakes. 


\section{Appendix B-Not for Publication}

\section{Instructions for the NP treatment without personal punishment}

\section{Overview}

This is an experiment in decision-making. Purdue University has provided funds for this research. The instructions are simple. If you follow them carefully and make good decisions, you can earn an appreciable amount of money. These earnings will be paid to you in cash at the end of the experiment.

We ask that you not talk with one another for the duration of the experiment. Please turn off your cell-phones. Do not use e-mail.

During the course of this experiment, you will be called upon to make decisions in several periods. The experiment is divided into five sequences of periods and each sequence is referred to as a cycle.

- $\quad$ At the beginning of a cycle, each participant in this room will be randomly assigned to a set.

- $\quad$ In each set there will be four persons.

- $\quad$ For the whole duration of a cycle, you will interact exclusively with the three other participants in that set and nobody else.

- You will never meet again these participants in the following cycles.

In each period of a cycle:

- In each period you will be matched to one other participant selected at random from the set you are assigned to. We will refer to this person as "your match."

- You will not be informed of the identity of your match. Hence, you do not know when you have already interacted with that person in previous periods of the same cycle.

- $\quad$ You and your match will interact according to the rules described in the upper portion of your screen. The rules will be explained in a moment. 
- $\quad$ After each period you will be re-matched to a participant chosen at random from the set you are assigned to. There is one chance out of three that you will be matched with any given person in your set.

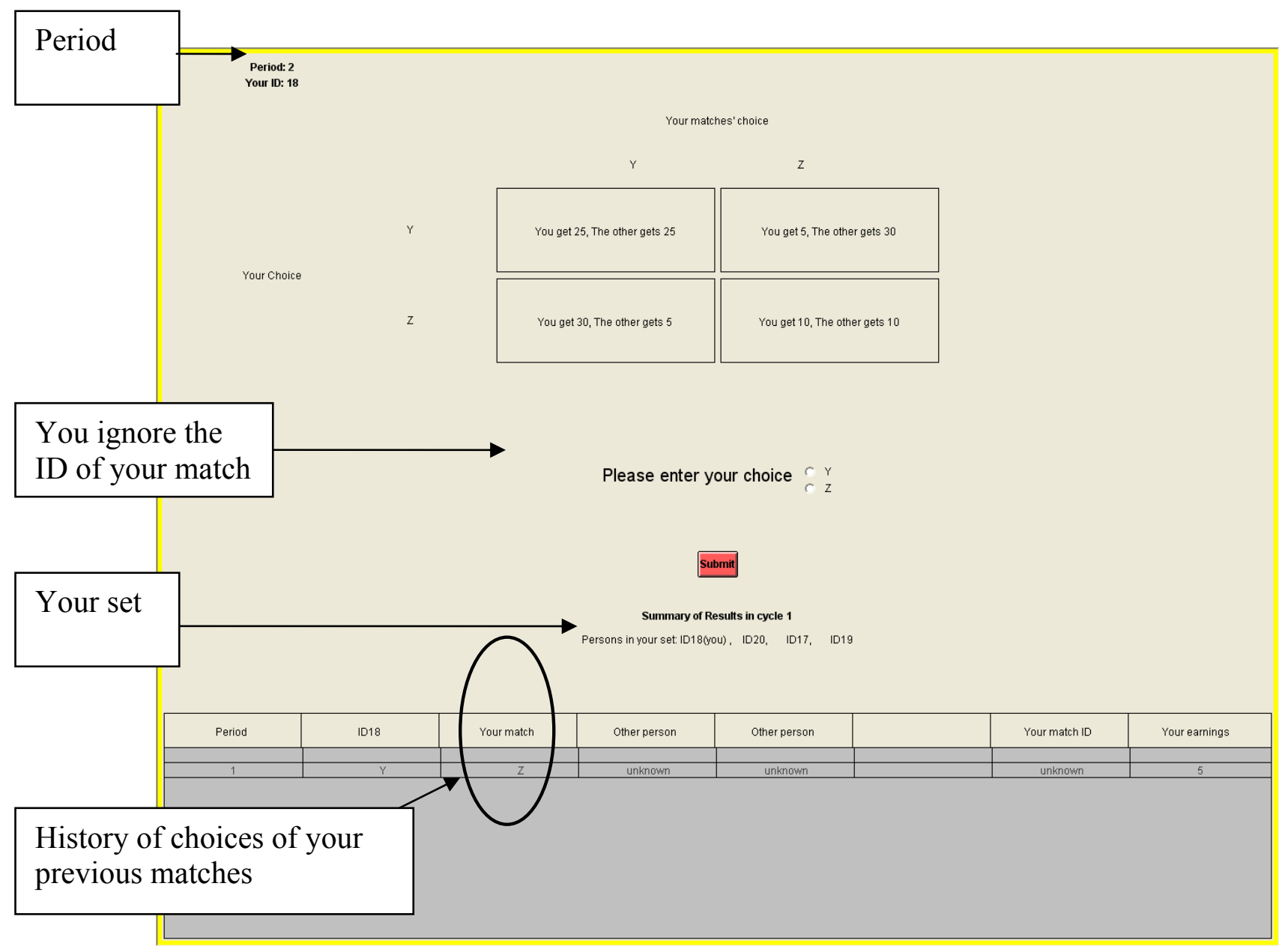

\section{$\underline{\text { Interaction rules }}$}

In a period you and your match can make either of two choices, $Y$ or $Z$. The points you earn in a period depend upon both the choice you make and the choice made by your match in that period. As the payoff table on your screen (above) indicates, there are four possible outcomes:

1. If both of you choose $\mathrm{Y}$ this period then: you both earn 25 points.

2. If you choose $Y$ this period and your match chooses $Z$ then: you earn 5 points and your match earns 30 points.

3. If you choose $\mathrm{Z}$ this period and your match chooses $\mathrm{Y}$ then: you earn 30 points and your match earns 5 points. 
4. If you both choose $Z$ then: you both earn 10 points.

To make your choice in each period, click the button next to either Y or Z. You may change your mind at any time prior to clicking the "Submit" button by simply clicking on the button next to $\mathrm{Y}$ or $\mathrm{Z}$. You are free to choose $\mathrm{Y}$ or $\mathrm{Z}$ in every period. When you are satisfied with your choice, click the "Submit" button. After all persons have made their choices, the results of the period will appear on your screen.

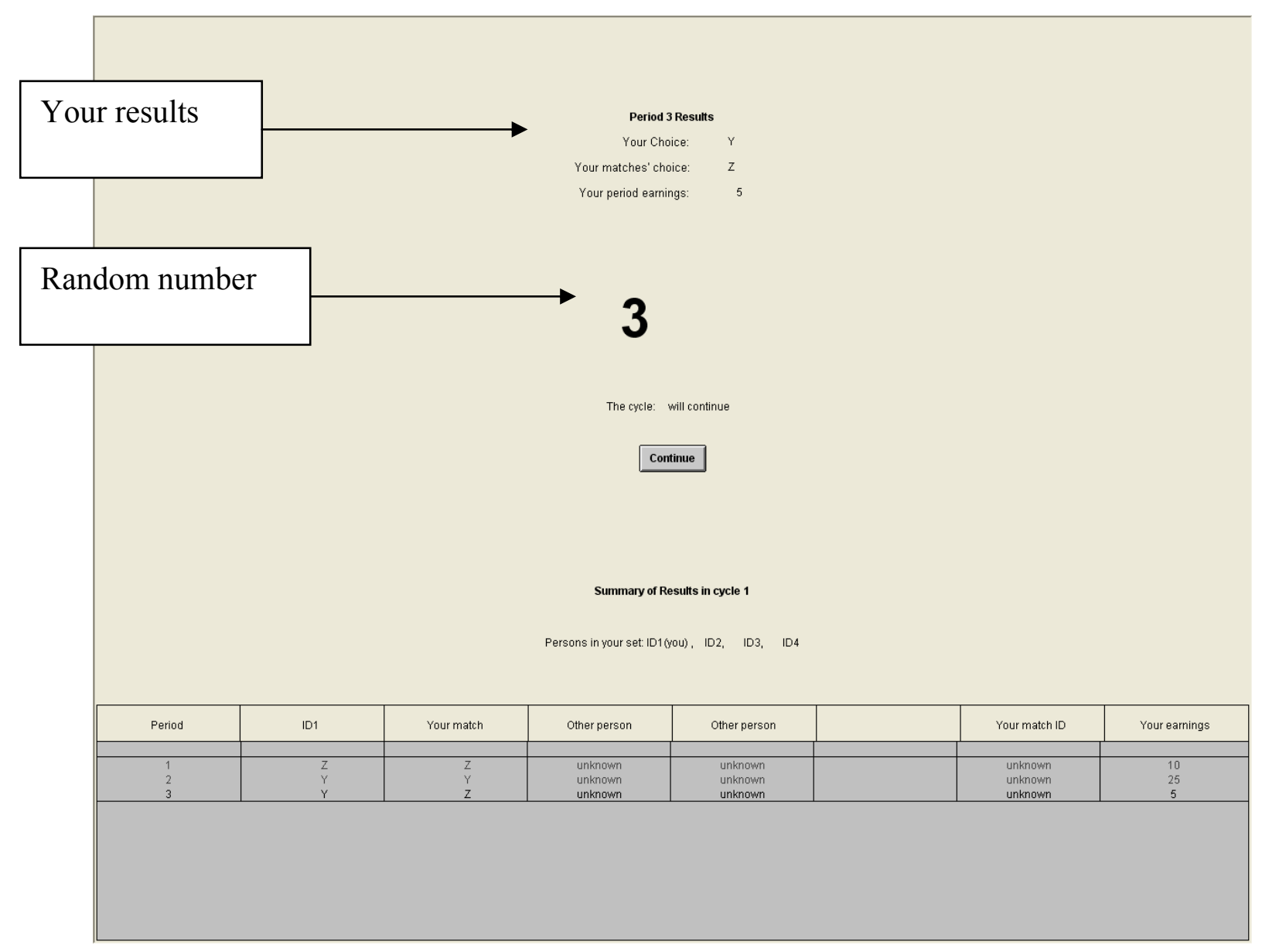

The result screen (above) will display the number of points you have earned for the period along with your choice and the choice of your match. The first column of the 'Summary of Results' table contains your past choices. The second column concerns the choices of your previous matches. Notice that choices in the second column were most likely made by different persons in different periods. You are not given information on the choices made by the other two persons in your set. Please record your results for the period on your RECORD SHEET under the appropriate headings. 
At this stage a ball will be drawn from an urn containing one hundred balls numbered from 1 to 100. Each ball is equally likely to be selected. The computer program will randomly draw a ball and show the number on the result screen (above). If this random number is less than or equal to 95 , then the cycle will continue into the next period. If this number is greater than 95 , then the cycle ends. Therefore, after each period there is a $95 \%$ chance that there will be another period of interactions in the cycle and a $5 \%$ chance that the cycle will end.

Suppose that a number less than or equal to 95 has been drawn. Then you press the "Continue" button to proceed. You will face the same decisional situation as in the previous period, but with a person selected at random from the set of participants you were assigned to. Remember that there are four participants in each set.

Before making your choice, you may review all the outcomes in previous periods of the cycle by scrolling down the "Summary of Results" table. The table shows your history and the past choices of the persons who happened to be your match in the period. You then choose either $\mathrm{Y}$ or Z. Your choice and the choice of your match this period are recorded and added to the Summary of Results table in the lower portion of your screen. You record the outcome and your point earnings for the period.

If the number drawn is greater than 95 then the cycle ends. When a cycle ends, you will be notified in a new screen. There will be a total of five cycles. The rules in the following cycles are the same as in the first, but you will interact with different persons. More precisely, after each cycle, new sets of persons will be formed. This assignment does not depend on actual choices. A participant will never interact with a person for more than one cycle.

\section{Earnings}

The points you earned in each period are added up. For every 10 points that you earn you will receive 13 cents $(\$ .13)$. Therefore, the more points you earn the more money you earn. In addition, you will receive a $\$ 10$ show-up fee. You will be paid your earnings in cash and in private at the end of today's session. 


\section{$\underline{\text { Final Comments }}$}

First, do not discuss your choices or your results with anyone at any time during the experiment.

Second, your ID\# is private. Do not reveal it to anyone.

Third, since there is a $95 \%$ chance that at the end of a period the cycle will continue, you can expect, on average, to interact for 20 periods in a given cycle. However, since the stopping decision is made randomly, some cycles may be much longer than 20 periods and some others may be much shorter.

Fourth, remember that after each period you will be matched randomly to someone in the set you were assigned to. As there are four people in the set, the probability of you being matched with the same person in two consecutive periods of a cycle is $1 / 3$. You are not told the identity of your match.

Fifth, the rules are the same in all five cycles. After a cycle, you will never meet again the same participants.

\section{Questions?}

Now is the time for questions. Does anyone have any questions before we begin? 


\section{Instructions for the PP treatment with personal punishment}

\section{$\underline{\text { Overview }}$}

This is an experiment in decision-making. Purdue University has provided funds for this research. The instructions are simple. If you follow them carefully and make good decisions, you can earn an appreciable amount of money. These earnings will be paid to you in cash at the end of the experiment.

We ask that you not talk with one another for the duration of the experiment. Please turn off your cell-phones. Do not use e-mail.

During the course of this experiment, you will be called upon to make decisions in several periods. The experiment is divided into five sequences of periods and each sequence is referred to as a cycle.

- $\quad$ At the beginning of a cycle, each participant in this room will be randomly assigned to a set.

- $\quad$ In each set there will be four persons.

- $\quad$ For the whole duration of a cycle, you will interact exclusively with the three other participants in that set and nobody else.

- $\quad$ You will never meet again these participants in the following cycles.

In each period of a cycle:

- In each period you will be matched to one other participant selected at random from the set you are assigned to. We will refer to this person as "your match."

- $\quad$ You will not be informed of the identity of your match. Hence, you do not know when you have already interacted with that person in previous periods of the same cycle.

- $\quad$ You and your match will interact according to the rules described in the upper portion of your screen. The rules will be explained in a moment.

- $\quad$ After each period you will be re-matched to a participant chosen at random from the set you are assigned to. There is one chance out of three that you will be matched with any given person in your set. 


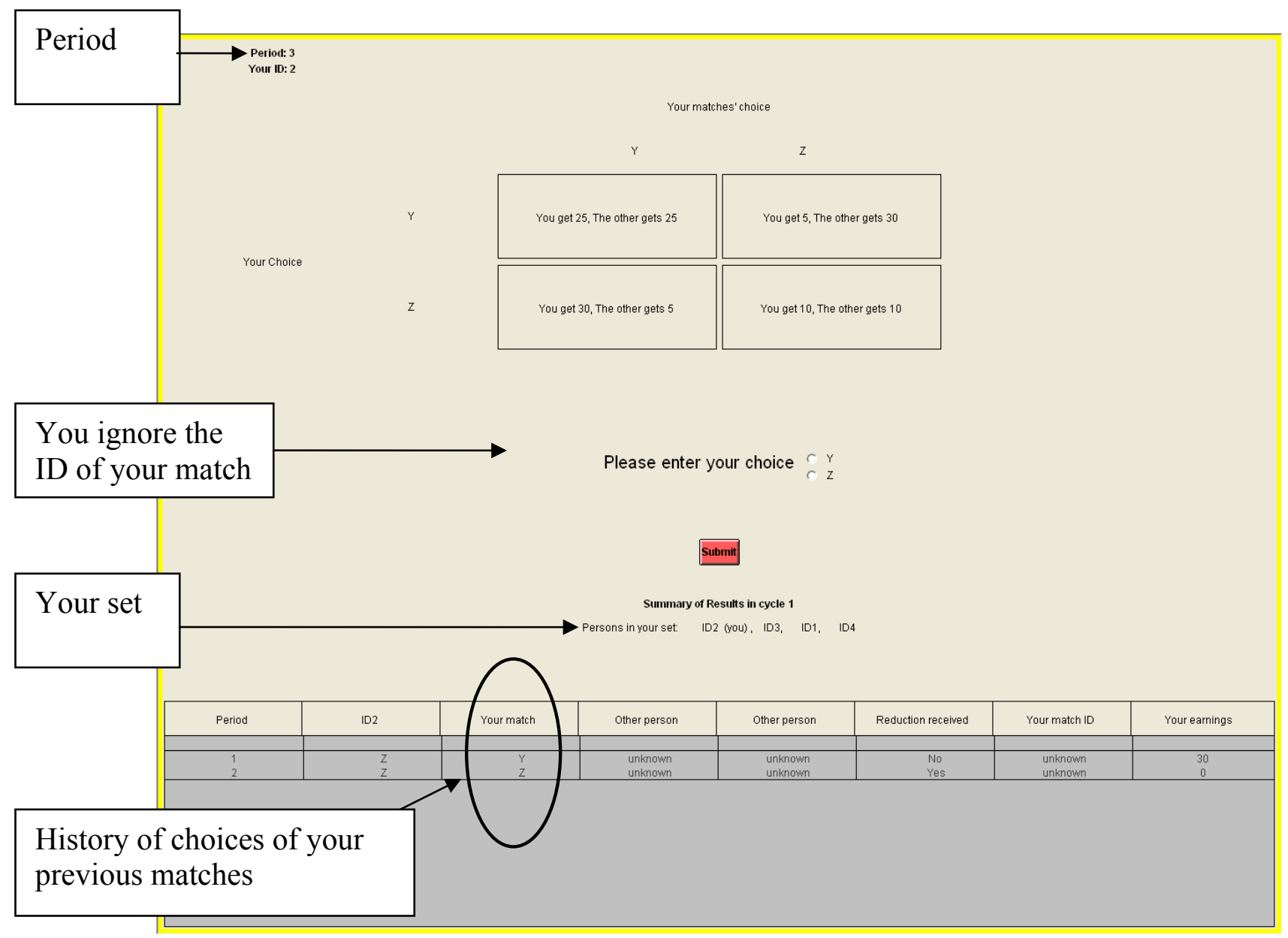

\section{$\underline{\text { Interaction rules }}$}

Each period is divided into two stages. In stage 1 you and your match can make either of two choices, Y or Z. The points you earn depend upon both the choice you make and the choice made by your match in that period. As the payoff table on your screen (above) indicates, there are four possible outcomes for stage 1:

1. If both of you choose $\mathrm{Y}$ this period then: you both earn 25 points.

2. If you choose $Y$ this period and your match chooses $Z$ then: you earn 5 points and your match earns 30 points.

3. If you choose $\mathrm{Z}$ this period and your match chooses $\mathrm{Y}$ then: you earn $\mathbf{3 0}$ points and your match earns 5 points.

4. If you both choose $\mathrm{Z}$ then: you both earn $\mathbf{1 0}$ points. 
To make your choice in stage 1, click the button next to either Y or Z. You may change your mind at any time prior to clicking the "Submit" button by simply clicking on the button next to $\mathrm{Y}$ or $\mathrm{Z}$. You are free to choose $\mathrm{Y}$ or $\mathrm{Z}$ in every period. When you are satisfied with your choice, click the "Submit" button. After all persons have made their choices, the results of stage 1 will appear on your screen (below).

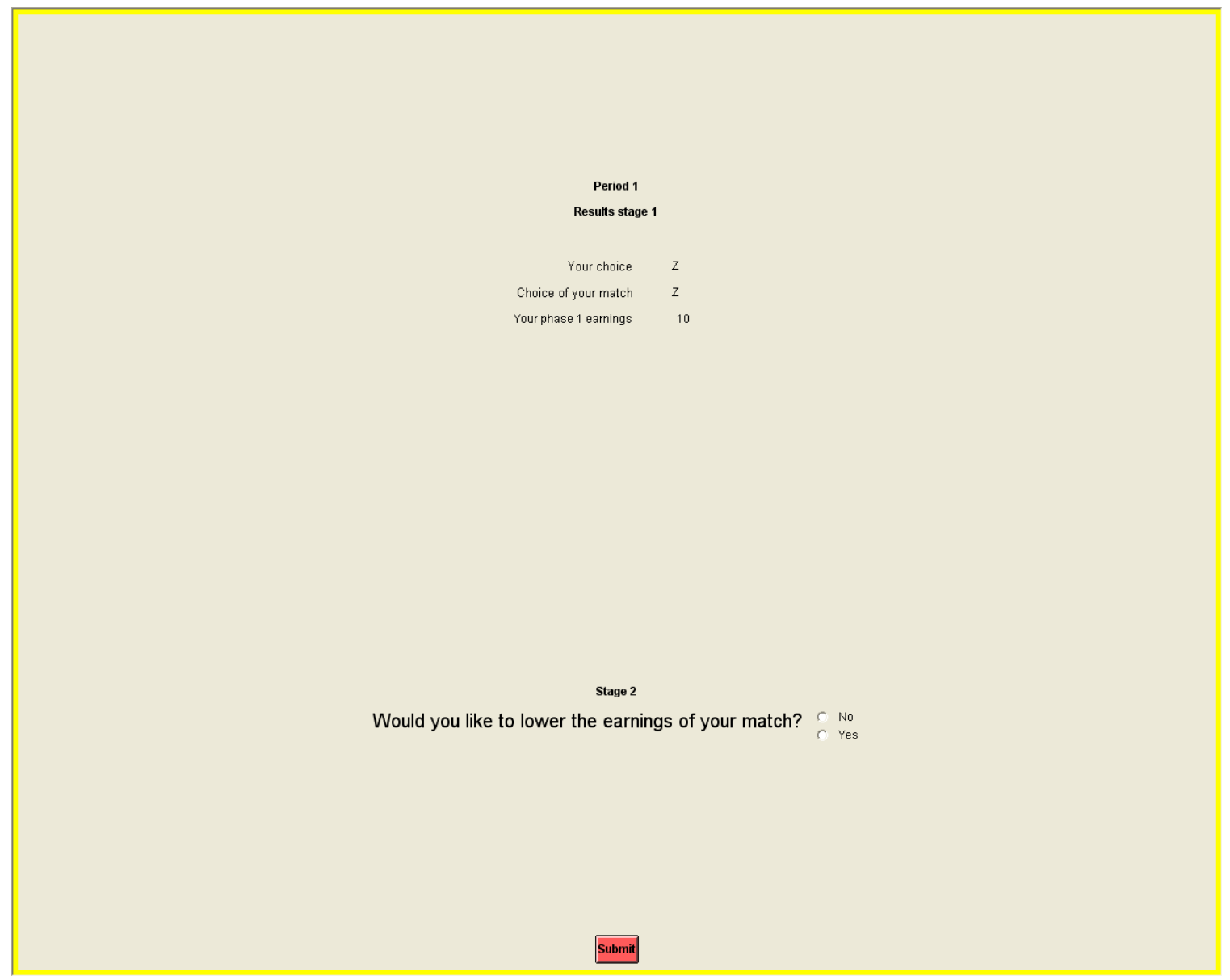

Before moving to another period, you have the opportunity to pay a cost to lower the earnings of your match (stage 2). You can click the button next to either NO or YES and then click submit when satisfied with your choice.

If you choose $\mathrm{NO}$, no points will be subtracted from the earnings of your match.

If you choose YES, 5 points will be subtracted from your earnings and 10 points will be subtracted from the earnings of your match.

After all persons have made their choices for stage 2, the final results of the period will appear on the lower portion of your screen (see screen below). Please notice that your period earnings can be negative. If your earnings in the period are negative, they will reduce your cumulative earnings. 


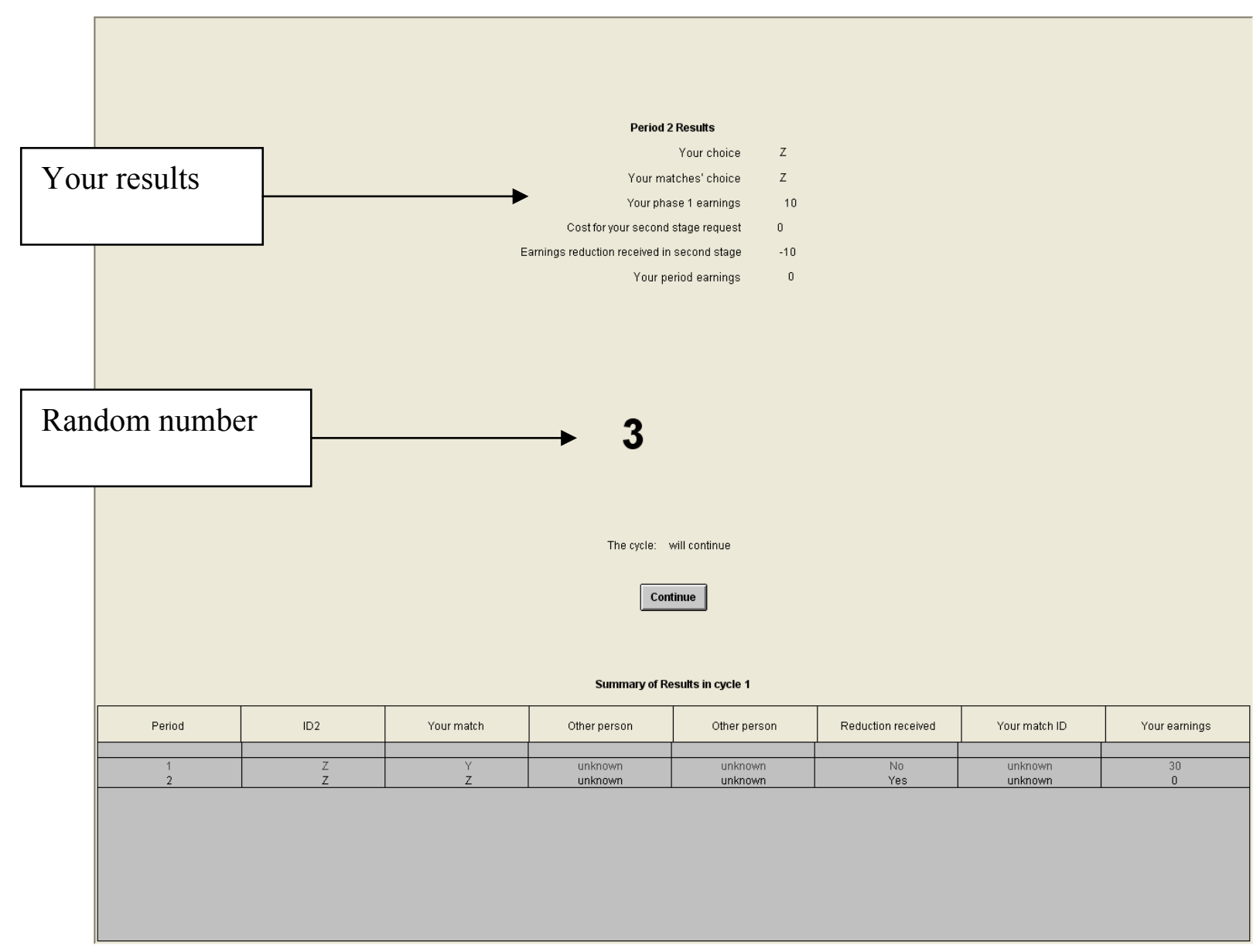

The result screen (above) will display the number of points you have earned for the period along with your choices and the choices of your match for both stage 1 and stage 2 . The first column of the 'Summary of Results' table contains your past choices in stage 1 . The second column concerns the choices in stage 1 of your previous matches. Notice that choices in the second column were most likely made by different persons in different periods. You are not given information on the choices made by the other two persons in your set. One of the columns lists the "Reduction received" in each period. It is marked "Yes" when your match requested to lower your earning and "No" otherwise. Please record your results for the period on your RECORD SHEET under the appropriate headings.

At this stage a ball will be drawn from an urn containing one hundred balls numbered from 1 to 100 . Each ball is equally likely to be selected. The computer program will randomly draw a ball and show the number on the result screen (above). If this random number is less than or equal to 95 , then the cycle will continue into the next period. If this number is greater than 95 , then the cycle ends. Therefore, after each period there is a $95 \%$ chance that there will be another period of interactions in the cycle and a $5 \%$ chance that the cycle will end. 
Suppose that a number less than or equal to 95 has been drawn. Then you press the "Continue" button to proceed. You will face the same decisional situation as in the previous period, but with a person selected at random from the set of participants you were assigned to. Remember that there are four participants in each set.

Before making your choice, you may review all the outcomes in previous periods of the cycle by scrolling down the "Summary of Results" table. The table shows your history and the past choices of the persons who happened to be your match in the period. You then choose either $\mathrm{Y}$ or Z in stage 1 and NO or YES in stage 2. Your choice and the choices of your match this period are recorded and added to the Summary of Results table in the lower portion of your screen. You record the outcome and your point earnings for the period.

If the number drawn is greater than 95 then the cycle ends. When a cycle ends, you will be notified in a new screen. There will be a total of five cycles. The rules in the following cycles are the same as in the first, but you will interact with different persons. More precisely, after each cycle, new sets of persons will be formed. This assignment does not depend on actual choices. A participant will never interact with a person for more than one cycle.

\section{Earnings}

The points you earned in each period are added up. For every 10 points that you earn you will receive 13 cents $(\$ .13)$. Therefore, the more points you earn the more money you earn. In addition, you will receive a $\$ 5$ show-up fee. You will be paid your earnings in cash and in private at the end of today's session. 


\section{$\underline{\text { Final Comments }}$}

First, do not discuss your choices or your results with anyone at any time during the experiment.

Second, your ID\# is private. Do not reveal it to anyone.

Third, since there is a $95 \%$ chance that at the end of a period the cycle will continue, you can expect, on average, to interact for 20 periods in a given cycle. However, since the stopping decision is made randomly, some cycles may be much longer than 20 periods and some others may be much shorter.

Fourth, remember that after each period you will be matched randomly to someone in the set you were assigned to. As there are four people in the set, the probability of you being matched with the same person in two consecutive periods of a cycle is $1 / 3$. You are not told the identity of your match.

Fifth, the rules are the same in all five cycles. After a cycle, you will never meet again the same participants.

\section{Questions?}

Now is the time for questions. Does anyone have any questions before we begin? 
QUIZ

1. The total number of cycles is

2. You are at the beginning of the cycle. How many periods do you expect the cycle will last, on average?

3. You are in period 15 of the cycle. How many additional periods do you expect, on average?

4. The number of participants in the experiment (total in the room) is

5. In a given cycle with how many participants could you interact with (i.e. number of people in a set)?

6. In a given period with how many participants do you interact with?

7. Other than your match, will you know at the end of the period the actions taken by people in your set?

8. Will you know at the end of the period the actions taken by participants outside your set?

9. Before choosing an action, will you know the ID of your match?

10. If ID 5 is in your set this cycle, is there any chance that ID 5 will be your match in future cycles?

11. How many points do you earn if both you and your match choose $\mathbf{Y}$ ?

12. If the experiment lasts 100 periods and everybody always chooses $\mathbf{Y}$, how many dollars are your going to earn?

13. How many points do you earn if you and your match choose $\mathbf{Z}$ ?

14. If the experiment lasts 100 periods and everybody always chooses $\mathbf{Z}$, how many dollars are your going to earn? 
ID

DATE

\section{RECORD SHEET}

\begin{tabular}{|c|c|c|c|c|c|c|c|}
\hline \multirow{2}{*}{ Cycle } & \multirow{2}{*}{ Period } & \multicolumn{2}{|c|}{ Stage 1} & \multicolumn{2}{|c|}{ Stage 2} & \multirow[b]{2}{*}{$\begin{array}{c}\text { Your } \\
\text { earnings }\end{array}$} & \multirow[b]{2}{*}{$\begin{array}{c}\text { Cumulative } \\
\text { earnings }\end{array}$} \\
\hline & & $\begin{array}{l}\text { Your } \\
\text { choice } \\
(\mathrm{Y} / \mathrm{Z})\end{array}$ & $\begin{array}{c}\text { Choice of } \\
\text { your } \\
\text { match } \\
(\mathrm{Y} / \mathrm{Z}) \\
\end{array}$ & $\begin{array}{c}\text { Your } \\
\text { choice } \\
\text { (no/yes) }\end{array}$ & $\begin{array}{c}\text { Choice of } \\
\text { your } \\
\text { match } \\
\text { (no/yes) }\end{array}$ & & \\
\hline & & & & & & & \\
\hline & & & & & & & \\
\hline & & & & & & & \\
\hline & & & & & & & \\
\hline & & & & & & & \\
\hline & & & & & & & \\
\hline & & & & & & & \\
\hline & & & & & & & \\
\hline & & & & & & & \\
\hline & & & & & & & \\
\hline & & & & & & & \\
\hline & & & & & & & \\
\hline & & & & & & & \\
\hline & & & & & & & \\
\hline & & & & & & & \\
\hline & & & & & & & \\
\hline & & & & & & & \\
\hline & & & & & & & \\
\hline & & & & & & & \\
\hline & & & & & & & \\
\hline & & & & & & & \\
\hline & & & & & & & \\
\hline & & & & & & & \\
\hline & & & & & & & \\
\hline & & & & & & & \\
\hline & & & & & & & \\
\hline & & & & & & & \\
\hline & & & & & & & \\
\hline & & & & & & & \\
\hline & & & & & & & \\
\hline & & & & & & & \\
\hline & & & & & & & \\
\hline & & & & & & & \\
\hline & & & & & & & \\
\hline & & & & & & & \\
\hline
\end{tabular}


2012

\section{Economic Science Institute Working Papers}

12-28 Camera, G. and Kim, J. Buyer's Equilibrium with Capacity Constraints and Restricted Mobility: A recursive approach.

12-27 Camera, G., Casari, M., and Bigoni, M. Binding Promises and Cooperation Among Strangers.

12-26 Schniter, E., Shields, T. and Dickhaut, J. Ageism \& Cooperation.

12-25 Gjerstad, S. and Smith, V. Balance Sheet Crises: Causes, Consequences and Responses.

12-24 Gómez-Miñambres, J., Corgnet, B. and Hernán-Gonzalez, R. Goal Setting and Monetary Incentives: When Large Stakes Are Not Enough.

12-23 Clots-Figueras, I., Hernán González, R., and Kujal, P. Asymmetry and Deception in the Investment Game.

12-22 Dechenaux, E., Kovenock, D. and Sheremeta, R. A Survey of Experimental Research on Contests, All-Pay Auctions and Tournaments.

12-21 Rubin, J. and Sheremeta, R. Principal-Agent Settings with Random Shocks.

12-20 Gómez-Miñambres, J. and Schniter, E. Menu-Dependent Emotions and Self-Control.

12-19 Schniter, E., Sheremeta, R., and Sznycer, D. Building and Rebuilding Trust with Promises and Apologies.

12-18 Shields, T. and Xin, B. Higher-order Beliefs in Simple Trading Models.

12-17 Pfeiffer, G. and Shields, T. Performance-Based Compensation and Firm Value: Experimental evidence.

12-16 Kimbrough, E. and Sheremeta, R. Why Can't We Be Friends? Entitlements, bargaining, and conflict.

12-15 Mago, S., Savikhin, A., and Sheremeta, R. Facing Your Opponents: Social identification and information feedback in contests.

12-14 McCarter, M., Kopelman, S., Turk, T. and Ybarra, C. Too Many Cooks Spoil the Broth: How the tragedy of the anticommons emerges in organizations.

12-13 Chowdhury, S., Sheremeta, R. and Turocy, T. Overdissipation and Convergence in Rent-seeking Experiments: Cost structure and prize allocation rules. 
12-12 Bodsky, R., Donato, D., James, K. and Porter, D. Experimental Evidence on the Properties of the California's Cap and Trade Price Containment Reserve.

12-11 Branas-Garza, P., Espin, A. and Exadaktylos, F. Students, Volunteers and Subjects: Experiments on social preferences.

12-10 Klose, B. and Kovenock, D. Extremism Drives Out Moderation.

12-09 Buchanan, J. and Wilson, B. An Experiment on Protecting Intellectual Property.

12-08 Buchanan, J., Gjerstad, S. and Porter, D. Information Effects in Multi-Unit Dutch Auctions.

12-07 Price, C. and Sheremeta, R. Endowment Origin, Demographic Effects and Individual Preferences in Contests.

12-06 Magoa, S. and Sheremeta, R. Multi-Battle Contests: An experimental study.

12-05 Sheremeta, R. and Shields, T. Do Liars Believe? Beliefs and Other-Regarding Preferences in Sender-Receiver Games.

12-04 Sheremeta, R., Masters, W. and Cason. T. Winner-Take-All and Proportional-Prize Contests: Theory and experimental results.

12-03 Buchanan, J., Gjerstad, S. and Smith, V. There's No Place Like Home.

12-02 Corgnet, B. and Rodriguez-Lara, I. Are you a Good Employee or Simply a Good Guy? Influence Costs and Contract Design.

12-01 Kimbrough, E. and Sheremeta, R. Side-Payments and the Costs of Conflict.

\section{1}

11-20 Cason, T., Savikhin, A. and Sheremeta, R. Behavioral Spillovers in Coordination Games.

11-19 Munro, D. and Rassenti, S. Combinatorial Clock Auctions: Price direction and performance.

11-18 Schniter, E., Sheremeta, R., and Sznycer, D. Restoring Damaged Trust with Promises, Atonement and Apology.

11-17 Brañas-Garza, P., and Proestakis, A. Self-discrimination: A field experiment on obesity.

11-16 Brañas-Garza, P., Bucheli, M., Paz Espinosa, M., and García-Muñoz, T. Moral Cleansing and Moral Licenses: Experimental evidence.

11-15 Caginalp, G., Porter, D., and Hao, L. Asset Market Reactions to News: An experimental study.

11-14 Benito, J., Branas-Garz, P., Penelope Hernandez, P., and Sanchis Llopis, J. Strategic Behavior in Schelling Dynamics: A new result and experimental evidence. 
11-13 Chui, M., Porter, D., Rassenti, S. and Smith, V. The Effect of Bidding Information in Ascending Auctions.

11-12 Schniter, E., Sheremeta, R. and Shields, T. Conflicted Minds: Recalibrational emotions following trust-based interaction.

11-11 Pedro Rey-Biel, P., Sheremeta, R. and Uler, N. (Bad) Luck or (Lack of) Effort?: Comparing social sharing norms between US and Europe.

11-10 Deck, C., Porter, D., and Smith, V. Double Bubbles in Assets Markets with Multiple Generations.

11-09 Kimbrough, E., Sheremeta, R., and Shields, T. Resolving Conflicts by a Random Device.

11-08 Brañas-Garza, P., García-Muñoz, T., and Hernan, R. Cognitive effort in the Beauty Contest Game.

11-07 Grether, D., Porter, D., and Shum, M. Intimidation or Impatience? Jump Bidding in On-line Ascending Automobile Auctions.

11-06 Rietz, T., Schniter, E., Sheremeta, R., and Shields, T. Trust, Reciprocity and Rules.

11-05 Corgnet, B., Hernan-Gonzalez, R., and Rassenti, S. Real Effort, Real Leisure and Real-time Supervision: Incentives and peer pressure in virtual organizations.

11-04 Corgnet, B. and Hernán-González R. Don’t Ask Me If You Will Not Listen: The dilemma of participative decision making.

11-03 Rietz, T., Sheremeta, R., Shields, T., and Smith, V. Transparency, Efficiency and the Distribution of Economic Welfare in Pass-Through Investment Trust Games.

11-02 Corgnet, B., Kujal, P. and Porter, D. The Effect of Reliability, Content and Timing of Public Announcements on Asset Trading Behavior.

11-01 Corgnet, B., Kujal, P. and Porter, D. Reaction to Public Information in Markets: How much does ambiguity matter?

\section{0}

10-23 Sheremeta, R. Perfect-Substitutes, Best-Shot, and Weakest-Link Contests between Groups.

10-22 Mago, S., Sheremeta, R., and Yates, A. Best-of-Three Contests: Experimental evidence.

10-21 Kimbrough, E. and Sheremeta, R. Make Him an Offer He Can't Refuse: Avoiding conflicts through side payments.

10-20 Savikhim, A. and Sheremeta, R. Visibility of Contributions and Cost of Inflation: An experiment on public goods.

10-19 Sheremeta, R. and Shields, T. Do Investors Trust or Simply Gamble? 
10-18 Deck, C. and Sheremeta, R. Fight or Flight? Defending Against Sequential Attacks in the Game of Siege.

10-17 Deck, C., Lin, S. and Porter, D. Affecting Policy by Manipulating Prediction Markets: Experimental evidence.

10-16 Deck, C. and Kimbrough, E. Can Markets Save Lives? An Experimental Investigation of a Market for Organ Donations.

10-15 Deck, C., Lee, J. and Reyes, J. Personality and the Consistency of Risk Taking Behavior: Experimental evidence.

10-14 Deck, C. and Nikiforakis, N. Perfect and Imperfect Real-Time Monitoring in a Minimum-Effort Game.

10-13 Deck, C. and Gu, J. Price Increasing Competition? Experimental Evidence.

10-12 Kovenock, D., Roberson, B., and Sheremeta, R. The Attack and Defense of Weakest-Link Networks.

10-11 Wilson, B., Jaworski, T., Schurter, K. and Smyth, A. An Experimental Economic History of Whalers' Rules of Capture.

10-10 DeScioli, P. and Wilson, B. Mine and Thine: The territorial foundations of human property.

10-09 Cason, T., Masters, W. and Sheremeta, R. Entry into Winner-Take-All and Proportional-Prize Contests: An experimental study.

10-08 Savikhin, A. and Sheremeta, R. Simultaneous Decision-Making in Competitive and Cooperative Environments.

10-07 Chowdhury, S. and Sheremeta, R. A generalized Tullock contest.

10-06 Chowdhury, S. and Sheremeta, R. The Equivalence of Contests.

10-05 Shields, T. Do Analysts Tell the Truth? Do Shareholders Listen? An Experimental Study of Analysts' Forecasts and Shareholder Reaction.

10-04 Lin, S. and Rassenti, S. Are Under- and Over-reaction the Same Matter? A Price Inertia based Account.

10-03 Lin, S. Gradual Information Diffusion and Asset Price Momentum.

10-02 Gjerstad, S. and Smith, V. Household Expenditure Cycles and Economic Cycles, 1920 - 2010.

10-01 Dickhaut, J., Lin, S., Porter, D. and Smith, V. Durability, Re-trading and Market Performance. 
09-11 Hazlett, T., Porter, D., and Smith, V. Radio Spectrum and the Disruptive Clarity OF Ronald Coase.

09-10 Sheremeta, R. Expenditures and Information Disclosure in Two-Stage Political Contests.

09-09 Sheremeta, R. and Zhang, J. Can Groups Solve the Problem of Over-Bidding in Contests?

09-08 Sheremeta, R. and Zhang, J. Multi-Level Trust Game with "Insider" Communication.

09-07 Price, C. and Sheremeta, R. Endowment Effects in Contests.

09-06 Cason, T., Savikhin, A. and Sheremeta, R. Cooperation Spillovers in Coordination Games.

09-05 Sheremeta, R. Contest Design: An experimental investigation.

09-04 Sheremeta, R. Experimental Comparison of Multi-Stage and One-Stage Contests.

09-03 Smith, A., Skarbek, D., and Wilson, B. Anarchy, Groups, and Conflict: An experiment on the emergence of protective associations.

09-02 Jaworski, T. and Wilson, B. Go West Young Man: Self-selection and endogenous property rights.

09-01 Gjerstad, S. Housing Market Price Tier Movements in an Expansion and Collapse.

\section{8}

08-09 Dickhaut, J., Houser, D., Aimone, J., Tila, D. and Johnson, C. High Stakes Behavior with Low Payoffs: Inducing preferences with Holt-Laury gambles.

08-08 Stecher, J., Shields, T. and Dickhaut, J. Generating Ambiguity in the Laboratory.

08-07 Stecher, J., Lunawat, R., Pronin, K. and Dickhaut, J. Decision Making and Trade without Probabilities.

08-06 Dickhaut, J., Lungu, O., Smith, V., Xin, B. and Rustichini, A. A Neuronal Mechanism of Choice.

08-05 Anctil, R., Dickhaut, J., Johnson, K., and Kanodia, C. Does Information Transparency Decrease Coordination Failure?

08-04 Tila, D. and Porter, D. Group Prediction in Information Markets With and Without Trading Information and Price Manipulation Incentives.

08-03 Thomas, C. and Wilson, B. Horizontal Product Differentiation in Auctions and Multilateral Negotiations.

08-02 Oprea, R., Wilson, B. and Zillante, A. War of Attrition: Evidence from a laboratory experiment on market exit. 
08-01 Oprea, R., Porter, D., Hibbert, C., Hanson, R. and Tila, D. Can Manipulators Mislead Prediction Market Observers? 